ISSN No. 0974-035X

An indexed refereed \& peer-reviewed journal of higher education

Towards Excellence

UGC-HUMAN RESOURCE DEVELOPMENT CENTRE

Gujarat University, Ahmedabad-380009, Gujarat, India

\title{
प्रदीपटीकामाधृत्य भारवेः पद्यविमर्शः
}

\section{Dr. Yogeshkumar Dilipbhai Trivedi}

शोधसार: :-

संस्कृतसाहित्यक्षेत्रे अड्गुलिगणनेव कालिदासप्रभृतिषु महाकविषु अन्यतमः भारविः । भारवेरर्थगौरवमिति ख्यातिः सुतरां सामअस्यं निर्वहति। अस्य महाकवेः अर्थगाम्भीर्यपूर्णस्य काव्यस्य प्राचीनैः ३६ व्याख्यातृभिः टीकाः विरचयामास इति उमेशप्रसादरस्तोगीवर्यः स्वशोधप्रबन्धे दर्शयति । एताषु टीकासु मल्लीनाथस्य ‘घण्टापथ' इति टीका नितरामुत्तमा। अत्र किरातपद्यान् आधृत्य टीकायाम् अर्थसड्गतौ कुत्रचित् शब्दशास्त्रदिशा असाधुत्वम्, कुत्रचित् शब्दस्य कोशासड्ग्गतिः तथा च समाप्त-पुनरातत्त्वदोषोदूवनं प्रतिपादितम् । एतादृशात् विषयान् आधृत्य १८ शताब्द्यां धर्मविजयगणिरचितप्रदीपटीकाडSधारेण विस्तरेण विमर्शो विहितः । शब्दविदां साहित्यरसिकानाग्च कृते नूनमयं विमर्शलेखः ज्ञानवर्धक आनन्दप्रदश्च भविष्यतीति मन्यामहे ।

मुख्यशब्दाः- किरातार्जुनीयम्, घण्टापथटीका, प्रदीपटीका, विमर्शः ।

प्रस्तावना:-

महाकाव्यकवीनां पड्न्तौ अनुकालिदासाश्वघोषं समयपर्यायनिर्देशात् कविवर- भारविरेव पपीरिव समुदेति संस्कृतसाहित्यनभसि । कविवरस्यास्य अर्थगामभीर्यपूर्णरचना-पाटवम्, सुललितपदवैभवं निर्दुष्टमनोहरपदविन्यासः कस्य वा सह्टदयस्य हृदयप्रदेशं नान्दो-लयति । 
पदलालित्यपारावारीणयस्य महाकविभारवेः अर्थगौरवसंयुतमिदं किरातार्जुनीयमहा-काव्यम् । महाकविभारवेः अधुना किरातार्जुनीयात्मिका एकैव संरचना प्राप्यते । काव्यमिदम् अर्थगौरवदृष्ट्या राजनीतिमर्मनिदर्शनबुद्ध्या चातिशेते काव्यान्तरम् । ओजोभावसहितश्चास्य वर्णनोपक्रमः । महाकाव्येउस्मिन् सकललक्षणानि समग्रतया अभिव्यक्तिं सम्प्राप्तानि दरीदृश्यन्ते। कृष्णकविना यथार्थोक्तं खलु-

'तदेव वृत्त्यापि महान्तमर्थं, प्रदर्शयन्ती रसमादधाना ।

सा भारवेः सत्पथदीपिकेव, रम्याकृतिः कैरिव नोपजीव्या'।। अर्जुनस्य तपस्यागमने शरदृतुवर्णनावसरे कीदृशीं सुसंश्लिप्टपूर्णाम् अद्वितीयकल्पनां पद्येऽस्मिन् प्राह -

$$
\begin{aligned}
& \text { मुखैरसौ विद्रुमभड्गलोहितैः शिखाः पिशंगीः कलमस्य बिभ्रती। } \\
& \text { शुकावलिर्व्यक्तशिरीषकोमला, धनुः श्रियं गोत्रभिदोडनुगच्छति1। }
\end{aligned}
$$

एतादृशाणि रक्यानि पदानि प्रतिसर्गं पदे पदे समुपलभ्यन्ते । कथावस्तु तु कविना महाभारतस्य वनपर्वतः सड्कलितम्, यद् द्वैतवनमधिवसतां पाण्डवानां तात्कालिकवृतान्तमधिकृत्य प्रवृत्तम् । तत्र च पाण्डवानामन्यतमस्य प्रकाण्डवीरस्यार्जुनस्य किरातरूपधारिणः पशुपतेः सकाशाद् मोघास्त्रोपलब्धिरूपं वृत्तमुगपुम्फितम् । अष्टादशसर्गरुपनिबद्धेरस्मिन् महाकाये इन्द्रकीलनामके पर्वते प्रवृत्तस्य शड्करार्जुनयोर्युद्धस्यातीव रोमहर्षणं वर्णनं कस्य न हृदयड्गमम् । अस्य काव्यस्यारम्भः श्रीशब्देनोपसंहारश्व लक्ष्मीपदेन कृतः । श्रृड्गारादिरसानां निरुपणं , शैलसूर्यास्तमनजलक्रीडादीनाज्च वर्णनमतीव मनोज्ञम् । स्वल्पै: पदैर्विशदार्थवर्णनमेव कवेरस्य वैशिष्ट्यम् ।

1 किरातार्जुनीयम् , चौखम्भाप्रकाशन, वारणसी, चतुर्थसर्गः, श्लोक सं. 36 
‘भारवेरर्थगौरवम्' इत्युक्तिरस्य विषये सुतरां सामअस्यमश्रुते। पाशुपतसंज्ञकास्त्रसंत्राप्तिपर्यवसानमेवास्य काव्यस्य फलत्वेनावसीयते ।

\section{टीकाविमर्श: :-}

किरातार्जुनीयमि'ति महाकाव्यमाधृत्य अधुनावधि प्राचीनैः ३६ विद्वद्विः टीकाः व्यरचिषत इति उमेशप्रसादरस्तोगीवर्यः स्वीये शोधग्रन्थे वर्णयति । तत्रापि वयं जानीमः यद् मल्लीनाथीया घण्टापथटीका सर्वत्र प्रसिद्धा । किरातकाव्यस्य विवेचनावसरे टीकाकारै: चितः पाठः एव नैकेषु स्थलेषु समुचितः प्रतिभाति यः पाठः घण्टापथे नोपलभ्यते । वयं अस्मिन् शोधविवरणे १८ शताब्यां पूर्वभागे आचार्यधर्मविजयगणिरचितां प्रदीपिकाटीकामाधृत्य किरातार्जुनीयस्य घण्टापथटीकायाः केषाश्चित् श्रोकानामुपरि समालोचनं कुर्महे। यद् अन्यस्यां टीकायाम् आहोस्विद् अन्यत्र कुत्रापि न केनापि चर्चितम् । तत्र कानिचन उदाहरणानि प्रस्तौमि ।

किराते चतुर्थसर्गे २२ तम्यां कारिकायां घण्टापथे एवं पाठः अस्ति -

\section{'उपैति सस्यं परिणामरम्यता ' नदीरनौद्धत्यमकता महीम् ।}

\section{नवैर्गुणैः सम्प्रति संस्तवस्थिरं तिरोहितं प्रेम घनागमश्रियः' $\mathrm{II}^{2}$}

घण्टापथटीकाSSधारेणास्य व्याख्या -- सस्यं त्रीह्यादिकं परिणामेन परिपाकेन या रम्यताम् उपैति । नदीरनौद्धत्यं रम्यरुपत्वमुपैति । मही चापड्कतां निष्पड्कत्वमुपैति । तथा हि संत्रति नवैर्गुणैः पूर्वोक्कैः शरद्धभैः संस्तवेन परिचयेन स्थिरं दृढमपि घनागमश्रियः प्रावृड्लक्ष्म्याः सम्बन्धि , तद्विषयत्वमित्यर्थः । प्रेम तिरोहितम् , निरर्थक कृतमित्यर्थः । गणतन्त्राः प्रेमाणो न परिचयतन्त्रा इति भावः। वास्तवालड्क्कारः ।।

\footnotetext{
2. कारिका -२२, किरात., घण्टापथटीका(आचार्यः मल्लिनाथः), चौखम्बा-प्रकाशनम्, वाराणसी
} 
अस्मिन् घण्टापथे ‘नदीः अनौद्धत्यम् उपैति’ इति कृत्वा कर्तृवाचकं ‘नदीः’ इति पदमुपात्तम्। अत्र च शब्दशास्त्रदृष्ट्या असाधुत्वापत्तिः भवति । किन्तु अस्याः समस्यायाः प्रदीपिकाटीकायां भिन्नदृष्ट्या समाधानं विहितम्, तच्च नूनं विदुषां मुदे भविष्यति । प्रदीपटीकायाम् ---

व्याख्या -- हे अर्जुन ! परिणामरम्यता परिपाकसुन्दरता सस्यं त्रीह्यादिधान्यम् उपैति प्राप्रोति । हे अर्जुन ! अनौद्धत्यम् । अपूरादिलक्षणम् अगम्यरुपत्वं सौम्यत्वमित्यर्थः । नदीः सरीत उपैति प्राप्रोति। हे अर्जुन ! अपड्कता निष्कर्दमत्वं महीं भूमिम् उपैति मही अपड्का जाता इत्यर्थः। तथाहि संप्रति अधुना नवैर्नूतनैर्गुणैः पूर्वोक्तै: शरद्गुणैः संस्तवस्थिरं चिरोपभोगेन परिचयेन वा दृढं घनागमश्रियः वर्षाकाललक्ष्म्याः सम्बन्धि प्रेम प्रीतिः तिरोहितम् अबाधितं निरर्थकं कृतमित्यर्थः। अत्र परिणामरम्यता सस्यम् उपैति , अनौद्धत्यम् नदीः उपैति , तथा अपड्कता महीम् उपैति । अत्र द्वितीयवाक्ये ' नदी: ' इति द्वितीयान्तं कर्मवाचकं पदम् , नानेन कापि शब्दसाधुत्वापतिः अर्थासड्गततिश्व । अतः पाठान्तरेणैव सड्ग्गतिः ज्यायान् पक्षः 1

द्वितीयस्थानं किरातस्य षष्ठसर्गे कारिकायां घण्टापथे 'क्क वनेचराः क्क निपुणा यतयः' इति पाठः, अत्र यतयः = विवेकबुद्धयः इत्यर्थः , 'यति' शब्दस्य सोऽर्थः न कोशसम्बद्धः अतः तत्स्थाने 'मतयः' इत्येव प्रस्तुतः पाठः।

पश्चदशे सर्गे २२-२३ इति द्वे कारिके प्रतिलोमानुलोमेन रचिता कविना। तथापि घण्टापथे २२ तम्यां कारिकायां तृतीये चरणे 'नः' इति पाठः स्वीकृतः । वस्तुतः २३ तम्याः 
कारिकायाः अनुसारेण तत्र ' न ' इति युक्तम् । प्रदीपिकायां ' न ' इति पाठं स्वीकृत्य एव व्याख्या कृता । पूर्वम् अनुलोमश्लोकं पश्यामः।

\section{तनुवारभसो भास्वानधीरोऽविनतोरसा ।}

\section{चारुणा रमते जन्ये कोऽभीतो रसिताशिनि ॥२३ ॥}

प्रदीपिकानुसारं व्याख्या -- हे गणाः ! कोऽभीतः सन् एवं लक्षणे जन्ये संग्रामे रमते न कोडपीत्यर्थः। यदि रमते तर्हि अर्जुन एव रमते इत्यर्थः। किं विशिष्टः अर्जुनः ? 'तनुवारभसः' तनुं वृणोतीति तनुवारं कवचं कार्ये अण् तेन भासते राजते इति तनुवारभसः वर्मणा शोभमानः पुनः किं अर्जुनः ? भास्वान् दीप्तिवान् तेजस्वीत्यर्थः। पुनः किम् अर्जुनः ? 'अधीरः' अः कृष्णस्तद्वद् धीरो धैर्यवान् (घण्टापथे - अधीरः धैर्यरहितः ) अत्र नूतनशब्दव्युत्पत्या श्लोकार्थः रमणीयताम् उपैति, पुनः किं अर्जुनः ? चारुणा मनोहरेण विनतोरसा उन्नतवक्षसोपलक्षितः किं . जन्ये ? रसिताशिनि रसितेन रवेणैव अश्नातीति तस्मिन् रसिताशिनी शब्दनैव जगत्प्राणहारिणीत्यर्थः। निर्भयसंवारात् एव अस्य निश्नलत्वं निश्चीयते इति वृत्तार्थः। एषा अनुलोमश्लोकव्याख्या।

\section{निशितासिरणोडभीको न्येजतेडमरणा रुचा।}

\section{सारतो न विरोधी न स्वाभासो भरवानुत।।२२ ।।}

प्रदीपिकानुसारं व्याख्या-- हे अमरणा मरणवर्जिता गणाः । एष मुनिः सारतो बलात् न विरोधी इति न अपि तु विरोधी एव। द्वौ नयौ प्रकृत्यर्थं सूचयतः। कथं ज्ञायते विरोधी इत्याह -- किं विशिष्टः अयम् अर्जुनः ? रुचा कान्त्या न्येजते तेजस्वितया निष्प्रकम्पो दृश्यते अतो भवद्दिरिपि स्थातव्यं न चलितव्यं किं . अयम् ? निशितासिरतः तीक्ष्णखड्गसक्तः पुनः किं ? अयम् ? स्वाभासः सुष्ठु आभासतेति स्वाभासः दर्शनीयः। पुनः किम् अयम् उत अत्यर्थं 
भरवान् भृ - भरणे भरतीति भर : भरोडस्यातीति भरवान् रमणभरसहिष्णुः स्वाभासः कवचादिभारयुक्त इत्यर्थः। प्रतिलोमश्लोकव्याख्या ।

घण्टापथटीकायाम् -- पूर्वोक्त-विशेषणयुक्तः अर्जुनः नः अस्माकं विरोधी शत्रुः सारतो बलतो न न्येजते न कम्पते न प्रचलतीतित्यर्थः। वस्तुतः २३ तम्याः कारिकायाः अनुसारेण अत्र नः इति स्थाने ‘न’ इति पाठं स्वीकृत्य पूर्वोक्तव्याख्यानुसारेणैव प्रतिलोमानुलोमश्रोकयोः व्याख्या युक्तिसड्ग्गता ।

किरातस्य प्रथमसर्गे ८ कारिकायां “समाप्तपुनरातत्वदोषः" अस्ति इति घण्टापथटीकायां निर्दिष्टम्। प्रदीपिका भिन्नरीत्या अर्थसंगतिं कृत्वा तस्य दोषस्य परिहारं करोति । पूर्वं घण्टापथदिशा दोषदर्शनं कुर्महे।

तथापि जिह्मः स भवजिगीषया तनोति शुभं गुणसंपदा यशः। समुन्नयन्भूतिमनार्यसंगमाद्वरं विरोधोऽपि समं महात्मभिः ॥C II व्याख्या - तथापि साशङ्कोऽपि जिह्मो वक्रः , वश्चक इति यावत् । स दुर्योधनो भवजिगीषया, गुणैर्भवन्तमाक्रमितुमिच्छयेत्यर्थः। “ हेतौ ' ' ( पा .२/ ३/ ३३ ) इति तृतीया । गुणसंपदा दानदाक्षिण्यादिगुणगरिम्णा करणेन शुभ्रं यशस्तनोति, स खलो गुणलोभनीयां त्वत्संपदमात्मसात्कर्तुं त्वत्तोऽपि गुणवतामात्मनः प्रगटयतीत्यर्थः । नन्वेवं गुणिनः सतोऽपि सज्जनविरोधो महानस्त्यस्य दोष इत्यशड्क्य सोऽपि सत्संसर्गालाभे नीचसंगमाद्वरमुत्कर्षा-वहत्वादित्याह समिति। तथा हि - भूतिं समुन्नयन् उत्कर्षमुत्पादयन् 
महात्मभिः समम् , सहेत्यर्थः। अनार्यसंगमाद् दुर्जनसंसर्गात् विरोधोऽपि वरं मनाक्पियः । अत्र मैत्यपेक्षया मनाक्प्रियत्वं विरोधस्य ‘भूतिं समुत्रयन्' इत्यस्य पूर्ववाक्यान्वये समाप्तस्य वाक्यार्थस्य पुनरादानात् समाप्तपुनरातत्त्वाख्यदोषापत्तिः। न च वाक्यान्तरमेतत् येनोक्तदोष - परिहारः स्यात् । अर्थान्तरन्यासोऽलंकारः। स च भूतिसमुन्नयनस्य पदार्थविशेषणद्वारा विरोधत्वं प्रति हेतुत्वाभिधान - रूपकाव्यलिड्गानुप्राणित इति॥८।

प्रदीपिकाटीकायां भिन्नपद्धत्या अस्य श्रोकस्य अर्थसंघटनं कृत्वा समाप्तपुनरातत्व-दोषस्य परिहारो वर्तते । वयं तद् पश्याम: ---

हे राजन् ! तथापि साशक्कोऽपि सुयोधनो जिह्मो वक्रः सन् भवजिगीषया गुणै: भवन्तमाक्रमयितुमिच्छया गुणसम्पदा गुणबाहुल्येन शुभ्रमुज्वलं यशः तनोति विस्तारयति यतः -- दानपुण्यफलाकीर्तिः पराक्रमान्वितं यशः। एकदिग्यापिनी कीर्तिः सर्वदिग्गामुकं यश इति॥८ ॥

स खलु दुर्जनो गुणलोभनीयां भवत्संपदं स्वायत्तीकर्तुं भवतोऽपि गुणवत्तात्मनः प्रकटीकरोतीत्यर्थः । स सुयोधनः किं कुर्वन् ? भूतिम् ऋद्धिं समुन्नयन् वर्धयन् उत्कर्ष सम्पादयत्तित्यर्थः यतः अनार्यसंगमात् महात्मभिः सज्जनैः समं सार्ध विरोधोऽपि क्लेशोऽपि वरं किश्चिदिष्टम् इति वृत्तार्थः।। 
अत्र टीकाकारेण कर्तुः विशेषणत्वेन ' भूतिं समुन्नयन् ' इत्यस्य अर्थसड्.घट्टनं कृतम् , अत्र नैतद् विरोधशब्दस्य विशेषणम्।

पश्चदशे सर्गे २३ इति कारिकायां प्रदीपिकायां या व्याख्या प्रदत्ता सा सुन्दरतमा सर्वथा भिन्ना च। शोधपत्रभूयस्त्वभिया नात्र तत्पल्लवयितुमुत्सहामहे ।

बहुषु स्थलेषु घण्टापथापेक्षया प्रदीपिकायां कृता विस्पष्टता, अर्थविस्तारः इत्यादि कमनीयोऽस्ति । उदाहरणरूपेण यथा- किरातस्य २ सर्गस्य ? ६ कारिकायाः अवतरणिका घण्टापथे एवमस्ति -

‘ननु समयः प्रतीक्ष्यते किं वेगेने’त्याह -

प्रदीपिकायाम् एवमस्ति ---

'ननु समयः प्रतीक्ष्यते किमौत्सुक्येने'त्यत्राह-

अत्र ‘वेगेन' इत्यस्यापेक्षया ‘औसुक्येन’ इति पदं सर्वथा औचित्यमावहमिति । किरातकाव्ये नैकानि सन्ति येषामभिनवार्थविस्तार: प्रदीपटीकायां समुपलभ्यते विस्तारभयादत्र अलमतिपल्लवेन ।।

\section{उपसंहारः-}

अत्र पत्रे किरातपद्यानां मल्लीनाथस्य घण्टापथटीकां तथा आचार्यधर्मविजयगणिवर्यस्य प्रदीपटीकामाधृत्य केषाश्चित् वैशिष्ट्यमावहतां पद्यटीकानां सविस्तरं विवरणं प्रास्तौत् । यत्र 
पद्यार्थानां नूतनदृष्ट्या वाक्यरचनां परिवर्त्य अर्थविचारः शब्दासाधुत्वनिरसनं क्वचित् शब्दस्य कोशानुगतीकरणम्, अन्यत्र पद्ये समाप्तपुनरातत्वदोषदर्शनपुरस्सरं तन्निरसनं तथा अन्यश्लोके अभिनवार्थविचारः प्रत्यपादि ।

अनेन विमर्शेण नाना पद्यार्थविषयेषु अभिनवमार्गाः दृष्टिपथमायान्ति, अत्र पद्यानामुदाहरणानि विस्तारभयाद् दिझ्मात्रेण दर्शितानि । 


$$
\text { संदर्भग्रन्थसूचि }
$$

१. ले. आचार्यमल्लीनाथ:,किरातार्जुनीयम्, घण्टापथटीका।

२. 'क्क वनेचराः क्क निपुणा मतयः' (प्रदीपिकाटीका )

३. ‘समाप्तपुनरादानात्समाप्तपुनरात्तकम्' ( काव्यप्रकाशः )

४. किरात. - किरातार्जुनीयम्।

\author{
Dr. Yogeshkumar Dilipbhai Trivedi. \\ Pradhyapak, \\ Department of Traditional Sanskrit Studies \\ The Maharaja Sayajirao University of Baroda \\ Mo. No. 9909283158 \\ Email-yogeshkeshod@gmail.com
}

